\title{
Xiakemycin A, a novel pyranonaphthoquinone antibiotic, produced by the Streptomyces sp. CC8-201 from the soil of a karst cave
}

\author{
Zhong-ke Jiang1, Lin Guo ${ }^{1}$, Chuan Chen, Shao-wei Liu, Lin Zhang, Su-juan Dai, Qi-yang He, Xue-fu You, \\ Xin-xin $\mathrm{Hu}$, Li Tuo, Wei Jiang and Cheng-hang Sun
}

The Journal of Antibiotics (2015) 68, 771-774; doi:10.1038/ja.2015.70; published online 24 June 2015

Pyranonaphthoquinone (PNQ) antibiotics represent an interesting family of biologically active secondary metabolites. The basic skeleton of PNQ antibiotics is the naphtho[2,3-c]pyran-5,10-dione ring system. PNQ lactones contain an additional $\gamma$-lactone ring fused to the dihydropyran moiety ${ }^{1}$ such lactoquinomycin A $(2)^{2}$ and its related aglycones, kalafungin (3), ${ }^{3}$ as shown in Figure 1. Many members of PNQ lactones were produced by actinomycetes, especially, Streptomyces spp., and found to be selective inhibitors of the serine-threonine kinase AKT, also known as protein kinase B. ${ }^{4}$

In the course of our screening for new antibiotics produced by actinomycetes from poorly explored habitats, a series of PNQ antibiotics with activity against Staphylococcus aureus ATCC 25923, were discovered from the secondary metabolites of a cave-derived actinomycete, CC8-201. The strain was isolated from the soil of a remote karst cave located at a suburb of Chongqing city, China, and was identified as a Streptomyces sp. based on a $16 \mathrm{~S}$ rRNA gene analysis (GenBank accession number: KJ480796). Their UV and visible (UV/Vis) spectra were similar to that of PNQ antibiotics such as 2 and 3. Under guidance of bioassay and UV/Vis spectra, fractionation and purification were conducted. As a result, a novel PNQ antibiotic was purified and identified. To the best of our knowledge, the compound is undoubtedly the first new antibiotic discovered from Chinese karst cave, hence, named as xiakemycin A (1) (Figure 1), in honor of Xia-ke Xu, the first explorer of karst caves in China. ${ }^{5}$ In this paper, we report the fermentation, isolation, physico-chemical properties, structural elucidation and bioactivities of 1 .

A stock culture of the strain Streptomyces sp. CC8-201 was maintained at $4{ }^{\circ} \mathrm{C}$ on YIM 38 agar slant consisting of yeast extract (Beijing Aoboxing Biotechnology, Beijing, China) $5.0 \mathrm{~g}$, malt extract (Beijing Aoboxing Biotechnology) $4.0 \mathrm{~g}$, glucose $4.0 \mathrm{~g}$, phenylalanine $0.001 \mathrm{~g}$, alanine $0.0003 \mathrm{~g}$, thiamine $0.001 \mathrm{~g}$, pyridoxine $0.001 \mathrm{~g}$, riboflavin $0.001 \mathrm{~g}$, niacin $0.001 \mathrm{~g}$, biotin $0.001 \mathrm{~g}, \quad \mathrm{FeSO}_{4} .7 \mathrm{H}_{2} \mathrm{O}$ $0.002 \mathrm{~g}, \mathrm{MnCl}_{2} .4 \mathrm{H}_{2} \mathrm{O} 0.001 \mathrm{~g}, \mathrm{ZnSO}_{4} \cdot 7 \mathrm{H}_{2} \mathrm{O} 0.001 \mathrm{~g}$ and agar $20.0 \mathrm{~g}$ in 1.01 distilled water ( $\mathrm{pH} 8.0){ }^{6}$ The stock culture was inoculated into $500 \mathrm{ml}$ Erlenmeyer flasks containing $100 \mathrm{ml}$ of seed medium, which was the same as above, but without agar. The flask culture was incubated on a rotary shaker (180 r.p.m.) at $28^{\circ} \mathrm{C}$ for $48 \mathrm{~h}$. One hundred milliliters of the flask culture was transferred to a $5000-\mathrm{ml}$ Erlenmeyer flask containing $1000 \mathrm{ml}$ of the producing medium, which contained the same ingredients as seed medium and was supplemented with 2\% soluble starch (Beijing Qi Te Xin Chemical Co. Ltd., Beijing, China). The fermentation was carried out at $28^{\circ} \mathrm{C}$ for $168 \mathrm{~h}$ on a rotary shaker ( 180 r.p.m.). One hundred liters of supernatant from the fermentation broth was absorbed on a column containing 10 1 Diaion HP-20 (Mitsubishi Chemical Holdings Corp., Tokyo, Japan) and the column was eluted successively with 301 each of distilled water, 30, 50 and $80 \%$ acetone-distilled water to yield four fractions (Fr. A-D). Fr. D (2.2 g) showed bioactivity and was subjected to gel chromatography on Sephadex LH-20 $\left(2.5 \times 100 \mathrm{~cm}^{2}\right.$, Pharmacia Company, Uppsala, Sweden) using methanol as eluant to further purify. The first brown bioactive fraction $(150 \mathrm{ml})$ was concentrated to give a brown material $(160 \mathrm{mg})$. After being dissolved in $1.6 \mathrm{ml}$ of methanol, the sample was filtered through a syringe filter unit with $0.22 \mu \mathrm{m}$ polytetrafluoroethylene (PTFE) membranes (Tianjin Jinteng Experiment Equipment Co., Ltd., Tianjin, China) and further purified by HPLC (Agilent 1200, Agilent Technologies Inc., Santa Clara, CA, USA) on a Zorbax SB-C18 column $\left(9.4 \times 250 \mathrm{~mm}^{2}, 5 \mu \mathrm{m}\right.$, Agilent Technologies Inc.) with methanol/water, $65: 35(\mathrm{v} / \mathrm{v})$ at $1 \mathrm{ml} \mathrm{min}^{-1}$. The peak at $R_{\mathrm{t}}=35 \mathrm{~min}$, with UV/Vis absorption maxima at 212,263, 355 and $444 \mathrm{~nm}$, was collected and pooled to yield $3 \mathrm{mg}$ of 1 as an orange powder.

Compound 1 was soluble in dimethyl sulfoxide, $\mathrm{MeOH}, \mathrm{CHCl}_{3}$ and $\mathrm{CH}_{3} \mathrm{CN}$. Its m.p. was $143-144^{\circ} \mathrm{C}(\mathrm{dec})$. The molecular formula of 1 was determined to be $\mathrm{C}_{22} \mathrm{H}_{20} \mathrm{O}_{8}$ by HR-ESI-MS $(\mathrm{m} / \mathrm{z}$, found $=$ 413.1231 $\left.[\mathrm{M}+\mathrm{H}]^{+}, \mathrm{calcd}=413.1231\right)$, which has thirteen degrees of unsaturation. 
The IR spectrum (film) of $\mathbf{1}$ exhibited absorption bands at 3266, 3212, 2977, 2934, 2956, 1784, 1656, 1622, 1585, 1467, 1366, 1230, $1066,792,764 \mathrm{~cm}^{-1}$, which indicated the presence of a lactone $\left(1784 \mathrm{~cm}^{-1}\right)$, a non-chelated quinone carbonyl group $\left(1656 \mathrm{~cm}^{-1}\right)$ and a chelated quinone carbonyl group $\left(1622 \mathrm{~cm}^{-1}\right)$. The UV/Vis absorption spectra in methanol showed maxima at $212(\varepsilon=44646)$, 263 (16 405), 355 (3558), 444 (4270). Comprehensive analysis of ${ }^{1} \mathrm{H}-\mathrm{NMR},{ }^{13} \mathrm{C}-\mathrm{NMR},{ }^{13} \mathrm{C}-{ }^{1} \mathrm{H}$ COSY and DEPT spectra of $\mathbf{1}$ indicated 22 carbon signals could be attributed to 5 oxygenated methine groups, 2 methylene groups, 2 methyl groups, 10 olefinic carbons, 2 carbonyl carbons and 1 ester carbonyl carbon. NMR data of 1 in $\mathrm{CDCl}_{3}$ (I) and $\mathrm{CD}_{3} \mathrm{OD}$ (II) were listed in Table 1.

The UV/Vis spectrum of $\mathbf{1}$ is similar to that of PNQ lactones, such as $\mathbf{2}$ and 3. NMR data comparison between $\mathbf{1}$ and $\mathbf{2}$ as shown in<smiles>CC1O[C@H]2CC(=O)O[C@@]2(C)C2=C1C(=O)c1c(O)ccc(C3=CC[C@@H](O)[C@H](C)O3)c1C2=O</smiles>

1<smiles>CC1OC(c2ccc3c(c2O)C(=O)C2=C(C3=O)[C@@H]3OC(=O)C[C@@H]3O[C@H]2C)CC(N(C)C)[C@H]1O</smiles>

2<smiles></smiles>

3

Figure $\mathbf{1}$ Structures of $\mathbf{1}$ (xiakemycin A), $\mathbf{2}$ (lactoquinomycin A) and $\mathbf{3}$ (kalafungin).

Table 1 NMR data of 1 (xiakemycin $\mathrm{A}$ ) in $\mathrm{CDCl}_{3}$ (I) and $\mathrm{CD}_{3} \mathrm{OD}$ (II) and NMR data comparison of common structural portions between xiakemycin $\mathrm{A}(1)$ and lactoquinomycin $\mathrm{A}(2)$ in $\mathrm{CDCl}_{3}$ *

\begin{tabular}{|c|c|c|c|c|c|c|}
\hline \multirow[b]{3}{*}{ Position } & \multicolumn{2}{|c|}{ Lactoquinomycin $A^{2}$} & \multicolumn{4}{|c|}{ Xiakemycin A } \\
\hline & \multicolumn{2}{|r|}{$\mathrm{CDCl}_{3}$} & \multicolumn{2}{|c|}{$\mathrm{CDCl}_{3}(\mathrm{I})$} & \multicolumn{2}{|r|}{$C D_{3} O D(I I)$} \\
\hline & $\delta_{C} a$ & $\delta_{H} b$ (mult, J $\left.H z\right)$ & $\delta_{C} c$ & $\delta_{H} d$ (mult, J Hz) & $\delta_{C} c$ & $\delta_{H} d(m u l t, \mathrm{~J} H z)$ \\
\hline 1 & 66.3 & $5.08(q, 7.0)$ & 66.2 & $5.04(q, 7.2)$ & 67.7 & $4.95(q, 7.2)$ \\
\hline $1 "$ & 18.8 & $1.57(\mathrm{~d}, 7.0)$ & 18.6 & $1.56(\mathrm{~d}, 7.2)$ & 18.5 & $1.51(\mathrm{~d}, 6.6)$ \\
\hline 3 & 66.5 & $4.69(\mathrm{dd}, 5.1,2.9)$ & 66.5 & $4.66(\mathrm{dd}, 4.8,3.6)$ & 68.1 & $4.71(\mathrm{dd}, 4.8,3.0)$ \\
\hline 4 & 68.7 & $5.25(\mathrm{~d}, 2.9)$ & 68.3 & $5.28(d, 3.6)$ & 70.6 & $5.33(\mathrm{~d}, 3.0)$ \\
\hline $4 a$ & 134.9 & - & 136.1 & - & 137.4 & - \\
\hline 5 & 180.8 & - & 181.5 & - & 183.1 & - \\
\hline $5 a$ & 129.7 & - & 129.0 & - & 131.3 & - \\
\hline 6 & 119.6 & $7.71(\mathrm{~d}, 7.8)$ & 130.9 & - & 131.4 & - \\
\hline 7 & 133.5 & $7.91(\mathrm{~d}, 7.8)$ & 139.9 & $7.56(d, 9.0)$ & 140.8 & $7.55(\mathrm{~d}, 8.4)$ \\
\hline 8 & 138.6 & - & 124.4 & $7.25(\mathrm{~d}, 9.0)$ & 124.6 & $7.19(\mathrm{~d}, 9.0)$ \\
\hline 9 & 157.7 & - & 162.5 & - & 163.3 & - \\
\hline $9-\mathrm{OH}$ & - & 12.20 (br s) & - & $12.32(\mathrm{~s})$ & - & - \\
\hline $9 a$ & 114.0 & - & 115.2 & - & 116.8 & - \\
\hline 10 & 187.8 & - & 188.4 & - & 190.1 & - \\
\hline $10 a$ & 149.2 & - & 148.2 & - & 149.3 & - \\
\hline $11 a$ & 37.0 & $2.69(\mathrm{~d}, 17.6)$ & 36.9 & $2.69(\mathrm{~d}, 18.0)$ & 37.7 & $2.49(\mathrm{~d}, 18.0)$ \\
\hline $11 b$ & & $2.97(\mathrm{dd}, 17.6,5.1)$ & & $2.95(\mathrm{dd}, 18.0,4.8)$ & & 3.09(dd, 18.0, 5.4) \\
\hline 12 & 173.5 & - & 174.0 & - & 177.2 & - \\
\hline $2^{\prime}$ & & & 75.9 & 4.20 (quint, 6.6) & 78.0 & $3.89(\mathrm{~m})$ \\
\hline $1 ", "$ & & & 17.2 & $1.28(\mathrm{~d}, 6.6)$ & 17.5 & $1.24(\mathrm{~d}, 6.6)$ \\
\hline $3^{\prime}$ & & & 67.1 & $3.80(\mathrm{~m})$ & 69.6 & $3.57(\mathrm{~m})$ \\
\hline 3'-OH & & & - & $3.31(\mathrm{~d}, 9.0)$ & - & - \\
\hline 4'a & & & 27.5 & $2.22(\mathrm{~m})$ & 31.8 & 2.12 (ddd, 17.4, 9.0, 3.0) \\
\hline $4^{\prime} b$ & & & & $2.50(\mathrm{~m})$ & & 2.46 (ddd, 17.4, 6.0, 4.8) \\
\hline $5^{\prime}$ & & & 95.9 & $4.83(\mathrm{dd}, 3.6,4.2)$ & 99.2 & $4.86(\mathrm{dd}, 4.8,3.0)$ \\
\hline $6^{\prime}$ & & & 151.1 & - & 154.1 & - \\
\hline
\end{tabular}

a. $100 \mathrm{MHz}$; b. $400 \mathrm{MHz}$; c. $125 \mathrm{MHz}$; d. $600 \mathrm{MHz}$

*NMR data of the substitution moiety at the C-8 position in lactoquinomycin A (2) did not shown in Table 1. 


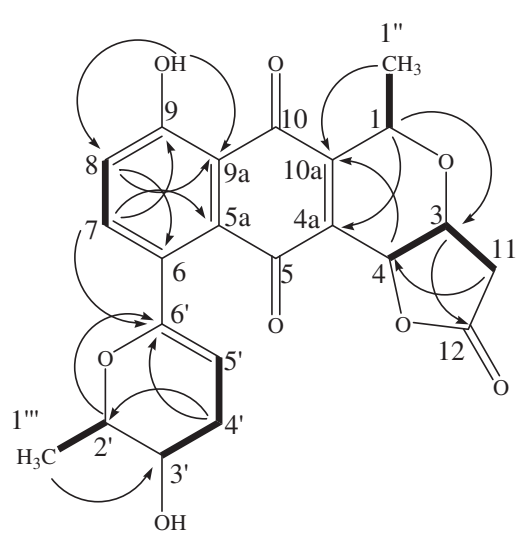

I

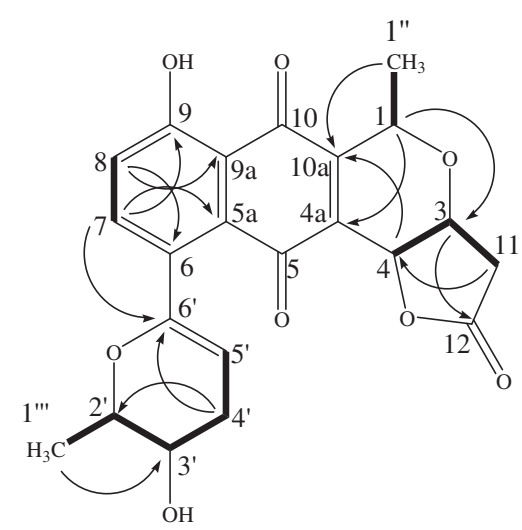

II

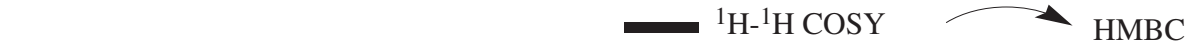

Figure 2 Summary of ${ }^{1} \mathrm{H}-{ }^{1} \mathrm{H}$ COSY and key $\mathrm{HMBC}$ correlations for 1 in $\mathrm{CDCl}_{3}(\mathrm{I})$ and in $\mathrm{CD}_{3} \mathrm{OD}(\mathrm{II})$.

Table 1 revealed the similarities of chemical structure between $\mathbf{1}$ and $\mathbf{2}$, and they are different in the substituted group and substituted position in juglone moiety. By careful analysis of $1 \mathrm{D}$ and 2D-NMR in both $\mathrm{CDCl}_{3}$ and $\mathrm{CD}_{3} \mathrm{OD}$ as shown in Figure 2, planar structure of 1 was elucidated as 6-substituted kalafungin.

The identification of Juglone moiety presented in $\mathbf{1}$ was started from two aromatic protons in ${ }^{1} \mathrm{H}-\mathrm{NMR}$ in $\mathrm{CDCl}_{3}: 7-\mathrm{H}$ at $\delta 7.56$ and $8-\mathrm{H}$ at $\delta 7.25$, which were readily observed. C-7 at $\delta 139.9$ and C-8 at $\delta 124.4$ were assigned by ${ }^{13} \mathrm{C}-{ }^{1} \mathrm{H}$ COSY in $\mathrm{CDCl}_{3}$. The two aromatic protons showed cross peak in ${ }^{1} \mathrm{H}-{ }^{1} \mathrm{H}$ COSY in $\mathrm{CDCl}_{3}$ and formed $\mathrm{AB}$ spin system with coupling constant as $9.0 \mathrm{~Hz}$, which demonstrated the existence of 1, 2, 3, 4-tetrasubstituted benzenoid ring. The other four aromatic carbons: C-9 at $\delta 162.5, \mathrm{C}-9 \mathrm{a}$ at $\delta 115.2, \mathrm{C}-5 \mathrm{a}$ at $\delta 129.0$ and $\mathrm{C}-6$ at $\delta 130.9$ were observed in DEPT and ${ }^{13} \mathrm{C}-\mathrm{NMR}$ spectra in $\mathrm{CDCl}_{3}$ and were assigned by tracing the cross peaks in $\mathrm{HMBC}$ in $\mathrm{CDCl}_{3}$ from $7-\mathrm{H}$ to $\mathrm{C}-5 \mathrm{a}$ and $\mathrm{C}-9$, from $8-\mathrm{H}$ to $\mathrm{C}-6$ and C-9a, from $9-\mathrm{OH}$ proton at 12.32 , which disappeared in ${ }^{1} \mathrm{H}-\mathrm{NMR}$ in $\mathrm{CD}_{3} \mathrm{OD}$, to C-8 and C-9a. Chemical shift of 9-OH proton at low field indicated the phenol hydroxyl proton formed intra-molecular hydrogen bonded with carbonyl group in peri-position, thus, C-10 at 188.4, chemical shift at relatively low field was assigned and formed juglone moiety of 1 with another carbonyl group, C-5 at 181.5, chemical shift at relatively high field.

Juglone moiety was fused with dihydropyran moiety of 1 by two olefinic carbons: C-4a at $\delta 136.1$ and C-10a at $\delta$ 148.2. The identification of the dihydropyran moiety was started from protons of 1 "- $\mathrm{CH}_{3}$ observed as a doublet signal at $\delta 1.56$ in ${ }^{1} \mathrm{H}-\mathrm{NMR}$ in $\mathrm{CDCl}_{3}$. By tracing the cross peaks from 1"- $\mathrm{H}$ to $1-\mathrm{H}$ at $\delta 5.04$, from $3-\mathrm{H}$ at $\delta 4.66$ to $4-\mathrm{H}$ at $\delta 5.28$ in ${ }^{1} \mathrm{H}-{ }^{1} \mathrm{H} \mathrm{COSY}$ in $\mathrm{CDCl}_{3}$, and the cross peaks between 1 "'- $\mathrm{H}$ and $\mathrm{C}-10 \mathrm{a}$, between $1-\mathrm{H}$ and $\mathrm{C}-4 \mathrm{a}$, between $4-\mathrm{H}$ and $\mathrm{C}-10 \mathrm{a}$ in $\mathrm{HMBC}$ in $\mathrm{CDCl}_{3}$, structural moiety as $\mathrm{CH}_{3}\left(1^{\prime \prime}\right)-\mathrm{CH}$ (1)-C(10a)-C(4a)-CH(4)-CH(3) was identified. The dihydropyran ring was closed by a oxygen atom between C-1 at $\delta 66.2$ and C-3 at $\delta 66.5$, which was further confirmed by a cross peak between $1-\mathrm{H}$ and C-3 observed in $\mathrm{HMBC}$ in $\mathrm{CDCl}_{3}$.

Dihydropyran ring was fused with $\gamma$-lactone moiety of 1 by $\mathrm{C}-3$ and C-4 at $\delta 68.3$, which were identified by tracing cross peaks from $3-\mathrm{H}$ to $11-\mathrm{H}_{\mathrm{a}}$ at $\delta 2.69$ and $11-\mathrm{H}_{\mathrm{b}}$ at $\delta 2.95$ in ${ }^{1} \mathrm{H}-{ }^{1} \mathrm{H}$ COSY in $\mathrm{CDCl}_{3}$. By tracing the cross peaks between $3-\mathrm{H}$ and $\mathrm{C}-12$, the ester carbonyl carbon at $\delta 174.0$, between $11-\mathrm{Ha}$ and $\mathrm{C}-4$ in $\mathrm{HMBC}$ in $\mathrm{CDCl}_{3}$, structural moiety as $\mathrm{CH}(4)-\mathrm{CH}(3)-\mathrm{CH}_{2}(11)-\mathrm{C}(12)$ was identified and further formed a $\gamma$-lactone ring closed by ester oxygen atom with $\mathrm{C}-4$. Thus, planar structure of 1 was elucidated as 6-substituted kalafungin.

Identification of 6-substituted group in $\mathbf{1}$ was started from 1 '"-H of a methyl group observed in ${ }^{1} \mathrm{H}-\mathrm{NMR}$ in $\mathrm{CDCl}_{3}$, as a doublet signal at $\delta 1.28$. By tracing the cross peaks from $1^{\prime \prime}$ - $\mathrm{H}$ to 2 '- $\mathrm{H}$ at $\delta 4.20$, from $2^{\prime}-\mathrm{H}$ to $3^{\prime}-\mathrm{H}$ (in $\mathrm{CD}_{3} \mathrm{OD}$ ), from $3^{\prime}-\mathrm{H}$ at $\delta 3.80$ to $4^{\prime}-\mathrm{H}_{\mathrm{a}}$ at $\delta 2.22$ and $4^{\prime}-\mathrm{H}_{\mathrm{b}}$ at $\delta 2.50$, from $4^{\prime}-\mathrm{H}$ to $5^{\prime}-\mathrm{H}$ at $\delta 4.83$ in ${ }^{1} \mathrm{H}-{ }^{1} \mathrm{H}$ COSY in $\mathrm{CDCl}_{3}$, structural moiety as $\mathrm{CH}_{3}$ (1'")- $\mathrm{CH}\left(2^{\prime}\right)-\mathrm{CH}\left(3^{\prime}\right)-\mathrm{CH}_{2}\left(4^{\prime}\right)-\mathrm{CH}\left(5^{\prime}\right)$ was identified and further confirmed by the cross peaks observed between $1^{\prime \prime}$ '- $\mathrm{H}$ and C-3' at $\delta 67.1$, between $4{ }^{\prime}-\mathrm{H}$ and C-2' at $\delta 75.9$ in HMBC in $\mathrm{CDCl}_{3}$.

A hydroxyl proton at $\delta 3.31$ as a doublet signal with coupling constant as $9.0 \mathrm{~Hz}$ in ${ }^{1} \mathrm{H}-\mathrm{NMR}$ in $\mathrm{CDCl}_{3}$, but disappeared in $\mathrm{CD}_{3} \mathrm{OD}$, indicated the hydroxyl group must attached to C-3', a oxygenated methine carbon in DEPT. Chemical shift of 2'-H and C-2' were at lower field than that of $3^{\prime}-\mathrm{H}$ and $\mathrm{C}-3$ ', which indicated $\mathrm{C}-2$ ' must attach to an oxygen atom and the oxygen atom must bind with C-6', a quaternary carbon, as a cross peak between 2'- $\mathrm{H}$ and C-6' was observed in $\mathrm{HMBC}$ in $\mathrm{CDCl}_{3}$. Chemical shift of C-5' at 95.9 and C-6' at 151.1 , together with a cross peak observed between $4^{\prime}-\mathrm{H}$ and C-6' in $\mathrm{HMBC}$ in $\mathrm{CDCl}_{3}$ revealed both $\mathrm{C}-6$ ' and $\mathrm{C}-5$ ' were olefinic carbon and bind each other to form a dihydropyran ring. Thus, the substitution moiety at the C-6 position was elucidated as 3-hydroxyl-2-methyl-2, 3-dihydropyran. The cross peak observed in HMBC between $7-\mathrm{H}$ and $\mathrm{C}-6$ ' linked the substituted group with juglone moiety of 1 through C-6' and C-6. Finally, the planar structure of 1 was elucidated as shown in Figure 1 , and the chemical name for $\mathbf{1}$ is 9-hydroxyl-6-(3-hydroxyl-2-methyl-2,3-dihydropyran) 1-methyl-1,3,4,11-tetrahydro-2H-furo[3,2-b]naphtho[2,3-d]pyran5,10,12-trione.

The relative stereochemistry of $\mathbf{1}$ was determined by analysis of NOESY in $\mathrm{CD}_{3} \mathrm{OD}$ (Figure 3). The cross peaks observed between 1 "- $\mathrm{H}$ and $3-\mathrm{H}$, between $3-\mathrm{H}$ and $4-\mathrm{H}$ demonstrated that 1 "'- $\mathrm{CH}_{3}$ and $3-\mathrm{H}$ were in axial orientation and $4-\mathrm{H}$ was in pseudo-equatorial orientation, the coupling constants between $3-\mathrm{H}$ and $4-\mathrm{H}$ as $3.0 \mathrm{~Hz}$ in $\mathrm{CD}_{3} \mathrm{OD}$ further confirmed the judgment. In addition, the cross peaks observed between $1^{\prime \prime}$ - $-\mathrm{H}$ and $3^{\prime}-\mathrm{H}$, between $3^{\prime}-\mathrm{H}$ and 4 ' $-\mathrm{H}_{\mathrm{b}}$, between $4^{\prime}-\mathrm{H}_{\mathrm{a}}$ and $2^{\prime}-\mathrm{H}$ revealed that $1^{\prime \prime}-\mathrm{CH}_{3}$ and $3^{\prime}-\mathrm{OH}$ were in pseudoequatorial orientation, $2^{\prime}-\mathrm{H}, 3^{\prime}-\mathrm{H}$ were in axial orientation, the 

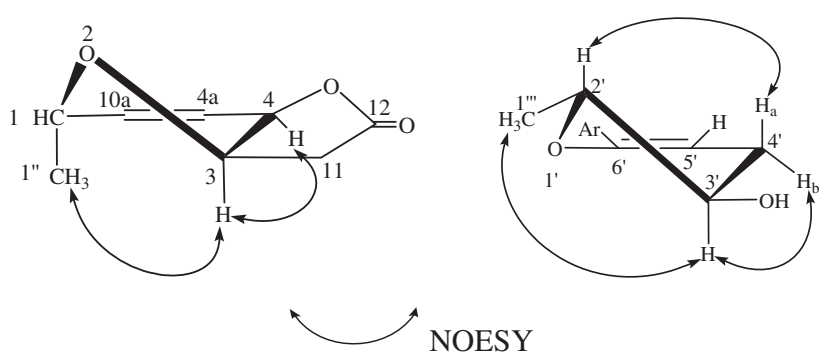

Figure 3 Key NOESY correlations of 1 in $\mathrm{CD}_{3} \mathrm{OD}$.

Table 2 Antibacterial activity of 1

\begin{tabular}{lc}
\hline Test organisms & MIC $\left(\mu \mathrm{gl}^{-1}\right)$ \\
\hline Staphylococcus aureus ATCC 29213 (MSSA) & 4 \\
Staphylococcus aureus ATCC 33591 (MRSA) & 4 \\
Staphylococcus aureus 15 (MSSA) & 4 \\
Staphylococcus aureus 12-28 (MSSA) & 8 \\
Staphylococcus aureus 12-33 (MRSA) & 8 \\
Staphylococcus epidermidis ATCC 12228 (MSSE) & 2 \\
Staphylococcus epidermidis 12-6 (MSSE) & 2 \\
Staphylococcus epidermidis 12-8 (MRSE) & 2 \\
Enterococcus faecalis ATCC 29212 (VSE) & 4 \\
Enterococcus faecalis ATCC 51299 (VRE) & 16 \\
Enterococcus faecalis 12-5 (VSE) & 16 \\
Enterococcus faecalis 09-9 (VRE) & 8 \\
Enterococcus faecium ATCC 700221 (VRE) & 16 \\
Enterococcus faecium 12-1 (VRE) & 8 \\
Enterococcus faecium 12-3 (VSE) & 16 \\
\hline
\end{tabular}

coupling constants between $4^{\prime}-\mathrm{H}_{\mathrm{a}}$ and $3^{\prime}-\mathrm{H}$ as $9.0 \mathrm{~Hz}$ in $\mathrm{CD}_{3} \mathrm{OD}$ further confirmed the judgment. Thus, the relative stereochemistry of 1 was determined as Figure 1.

The MIC values against Gram-positive bacteria of 1 were listed in Table 2, compound $\mathbf{1}$ showed strong inhibitory activities against Gram-positive bacteria, but exhibited weak activities against Candida parapsilosis ATCC22019, Candida albicans CCTCCAY93025,
Cryptococcus laurentii CCTCCAY91013 and Candida tropical CCTCCAY91009, with MIC values $\geqslant 64 \mu \mathrm{g} \mathrm{ml}^{-1}$. MICs were determined by agar disk dilution method according to Clinical and Laboratory Standards Institute. ${ }^{7,8}$ The cytotoxicities of $\mathbf{1}$ in vitro against human lung cancer A549 cells, breast cancer MCF-7 cells, hepatoma HepG-2 cells, cervical cancer HeLa cells, colon carcinoma HCT-116 cell p53 wt cells, neuroblastoma SH-SY5Y cells and human prostate cancer PC-3 cells were measured by the methylthiazolyldiphenyl-tetrazolium bromide assay. ${ }^{9}$ Compound $\mathbf{1}$ exhibited in vitro cytotoxicity with $\mathrm{IC}_{50}$ values of $2.77,1.82,1.54$, $0.98,0.59,0.55$ and $0.43 \mu \mathrm{M}$, separatively.

\section{ACKNOWLEDGEMENTS}

This work was supported by the National Natural Sciences Foundation of China (NSFC, Grant No.81172963 and 81373308), the National Science and Technology Major Project (Grant no. 2012ZX09301002-001-018) from the Ministry of Science and Technology of China, Specialized Research Fund for the Doctoral Programme of Higher Education (SRFDP, Grant No.

20111106110032) from the Ministry of Education of China, Beijing Natural Science Foundation (Grant no.7133249) and IMB grant (IMBF201407).

1 Brimble, M. A., Duncalf, L. J. \& Nairn, M. R. Pyranonaphthoquinone antibioticsisolation, structure and biological activity. Nat. Prod. Rep. 16, 267-281 (1999).

2 Okabe, T. et al. Lactoquinomycin, a novel anticancer antibiotic II. Physico-chemical properties and structure assignment. J. Antibiotics 38, 1333-1336 (1985).

3 Johnson, L. E. \& Dietz, A. Kalafungin, a new antibiotic produced by Streptomyces tanashiensis strain Kala. Appl. Environ Microb 16, 1815-1821 (1968).

4 Salaski, E. J. et al. Pyranonaphthoquinone lactones: a new class of AKT selective kinase inhibitors alkylate a regulatory loop cysteine. J. Med. Chem. 52, 2181-2184 (2009).

5 Ravbar, N. The earliest Chinese karstologist xu xiake. Acta. Carsologica. 32, 243-254 (2003).

6 Jiang, Y. et al. Streptomyces hainanensis sp. nov., a novel member of the genus Streptomyces. Int. J. Syst. Evol. Microbiol. 57, 2694-2698 (2007).

7 Clinical and Laboratory Standards Institute. Performance Standard for Antimicrobial Disk Susceptibility Tests; Approved Standard-11th edn. CLSI document M02-A11 (Clinical and Laboratory Standards Institute, 2012).

8 Clinical and Laboratory Standards Institute. Performance Standards for Antimicrobial Susceptibility Testing; Twenty-Third Informational Supplement. CLSI document M100-S23 (Clinical and Laboratory Standards Institute, 2014).

9 Mosmann, T. Rapid colorimetric assay for cellular growth and survival: application to proliferation and cytotoxicity assays. J. Immunol. Methods. 65, 55-63 (1983).

Supplementary Information accompanies the paper on The Journal of Antibiotics website (http://www.nature.com/ja) 